\title{
Emergency Vehicle Priority Preference at Multiple Wireless Network Sensors (MWNS) Intelligent Road Traffic Signal Control System
}

\author{
Okunade Oluwasogo Adekunle ${ }^{1}$, Osunade Oluwaseyitan ${ }^{2}$ \\ ${ }^{1}$ School of Science and Technology, National Open University of Nigeria, 14/16, Ahmadu Bello Way, Victoria \\ Island, Lagos, Nigeria. \\ ${ }^{2}$ Department of Computer Science, University of Ibadan, Ibadan, Nigeria.
}

\begin{abstract}
Traffic control management system has to be intelligent and equitable in signal allocation management system, especially priority order has to be given to emergency vehicles so as to prevent unforeseen circumstances, likeaccident and delay in emergency duties delivery. However we apply multiple wireless network sensors (MWNS) to intelligently control the road traffic system for equitable allocation of time frame; and to dynamically give priority preference to any sighted emergency vehicle on the road at any point in time; this will enable emergency vehicles to pass through signalized intersections withfewer interruptions from surrounding vehicular traffic. This approach increases road capacity, traffic flow, prevents traffic congestions, accident and thus increases society economic growth.
\end{abstract}

Keywords: Intelligent, Priority, emergency, Trafficlllumination, Radio frequency Identification Reader (RFIR), Multiple Wireless Network Sensors (MWNS)

\section{Introduction}

Predetermined timing schemes of traffic control system has become order of todays' traffic control system, where control system remain fixed until further resetting is required, irrespective of variance in road track congestion and emergency need (in time of ambulances, fire brigade, various form of accidents and so on). This has instigated an idea and scenarios to solve the traffic emergency control problem, by designing Emergency Vehicle Priority Preference at Intelligent Road Traffic Signal Control System Using Multiple Wireless Network Sensors (MWNS) where the emergency vehicles will be consider first based on calculated arrival time at the crossroad.

Development in urban cities brings about increment in automobiles and growing of traffic which leads to traffic conflict; It became tedious job for the traffic officer to control the traffic in a city like Lagos, Nigeria wheretraffic control systems are not meeting the present day traffic density. According to [1]the existing methods for traffic management surveillance and control are not adequately efficient in terms of the performance, cost, and the effort needed for maintenance and support. For example, the 2007 Urban mobility report estimates total annual cost of congestion for the 75 U.S. urban areas at 89.6 billion dollars, the value of 4.5 billion hours of delay and 6.9 billion gallons of excess fuel consumed; Traffic congestion causes great financial losses, health hazards and environmental pollution [2], which has negative effects on National Economic Growth. Mismanagement and traffic congestion results in long waiting times, loss of fuel and money. It is therefore utmost necessary to have a fast, economical and efficient traffic control [3].

During peak hours, most of the crossroads are blocked with long queueof vehicles without movement at all;just because they have Red illumination "ON"; whereas some other roads with less or no traffic volume are traffic free just because they have Green illumination "ON"; due to lack of intelligence of the existing traffic system. Whereas, the fundamental principle of urban traffic control system is to be able to respond to dynamic changes of the traffic demand. Also, emergency vehicles may have to be delayed or wait unnecessarily just because vehicles ahead of it may have to wait as a result of red illumination "ON" perhaps emergency vehicles may end up claiminglife and cause collision while trying to enforce itself "ON" when green illumination is "OFF" due to its level of emergency.An analysis of the current traffic control system in the South Eastern Nigerian city shows that some of the junctions are controlled by traffic wardens while some are not manned at all, some of these junctions also have traffic signals strategically located but are not intelligent [4]. Moreover, there is no effective intelligent traffic system that works twenty four hours (day and night) to effectively control signals at these busy junctions [4].

Traffic load is highly dependent on parameters such as time, day, season, weather and unpredictable situations such as accidents, special events or construction activities. If these parameters are not taken into account, the traffic control system will create bottlenecks and delays. A traffic control system that 
solves these problems by continuously sensing and monitoring traffic conditions and adjusting the timing of traffic lights according to the actual traffic load is called an intelligent traffic control system[5].

According to [6] urban population of more than 10 million people require planners to collect and manage traffic data on 24 hours 7 days per week basis.Improper control of traffic congestion could result into lossof time, opportunities miss, frustration, loss oforganizational productivity cost by the workers, trade opportunities loss, delivery delay, which goes on increasing and contribute negatively to National economy growth [7.Several measurement has been introduced by the Government to reduce delays experienced by drivers at intersections such as construction of flyovers, ring shaped roads, restriction of large vehicles in the city, introduction of one way roads, traffic controlling by the traffic officer and automatic signal controlling systems[2].The present traffic system has fixed time interval for green and red signal illumination, controllers are based on old microcontroller such as AT89C51 which has very less internal memory and no in-built ADC [8] which does not provide the required flexibility to the system.

Traffic Light Controlis the process by which the electronic signals are being used to control the traffic flow at the road intersections to maintain easy flow of traffic. Local time based traffic controllers must be monitored and field adjusted periodically to ensure efficient traffic operations[9]; this could be tedious in practice which lead us to this research work.

Different approaches /tools among which can be used for the implementation of intelligent road traffic signal management system and emergency vehicle priority preference is fuzzy logic; is a powerful tool for processing non-deterministic and non-linear problems. It can represent fuzzy and qualitative knowledge, and so it can imitate human reason logic. Itdeals with uncertainty in Engineering by attaching degrees of certainty to answer to logical questions [10]; it has the capability of mimicking human intelligence [2]. Fuzzy controller usesvehicle loop detectors, to measure approaches flows and estimate queues where it data can be used to decide, at regular time intervals, whether to extend or terminate the current signal phase.

Also an expert system uses a set of given rules to decide upon the next action; in traffic signal control system, it can be used to change some of the control parameters. The expert systems can communicate to allow for synchronization, performance on the network depends on the rules that are used, for each traffic light controller, the set of rules can be optimized by analyzing how often each rule fires, and the success it has. The system could even learn new rules[11]describes dynamic and automatic traffic light control using forward chaining type of reasoning approach.

Artificial neural network (ANN) has the capabilities such as non-linear mapping (or generalization), self-adapting, self-organizing and self-learning. Due to this, it has been widely used in many fields such as signal and information processing, pattern recognition and automatic control[10]. The remainder of this paper is organized as follows; Section 2 introduce the framework for the Emergency Vehicle Priority Preference on Intelligent Road Traffic Signal Control System Using Multiple Wireless Network Sensors (MWNS), Section 3 describe the result of the frame work,Section 4 discuss the result derived from the given framework in Section 2, while Section 5 discussthe summary. Finally, conclusion is discussed in Section 6.

\section{Methodology}

Implementation of signal priority has the potential to reduce control delay caused by traffic signals since significant amount of delay to transit vehicles in urban areas is caused by traffic signals [11]. However we propose an efficient communication and control system that coordinate the operation of road traffic system components in a manner that work on both single and multiple road intersections. Each sensor node placed by the roadsides of the proposed scheme will mainly collect it data and send it to central processor in a real time, via wireless access and generate permitted traffic length through the traffic signal, by calculating the number of sensor(s) contacted vehicles by assigning designated value of six (6) to each contacted car, and multiply it with the number of contacted sensors (readers) (x), to be generated by the number of contacted sensor(s); that is $\left(6^{*} \mathrm{x}\right)=$ Green light Illumination per circle in Seconds. The result generated here will be green light permitted time interval per seconds, however this will be reset per calculation cycle. In term of emergency vehicle, system monitors the emergency vehicle's location and provides estimated arrivals time, using the contacted sensor (out of (10) ten available sensors) distance from the cross road. And reset the cycle, given priority to the present emergency track first, based on the calculated arrival time (while other tracks RED illumination is "ON", emergency track GREEN Illumination will be "ON"). Then system will reset to normal after the departure of the emergency vehicle. 


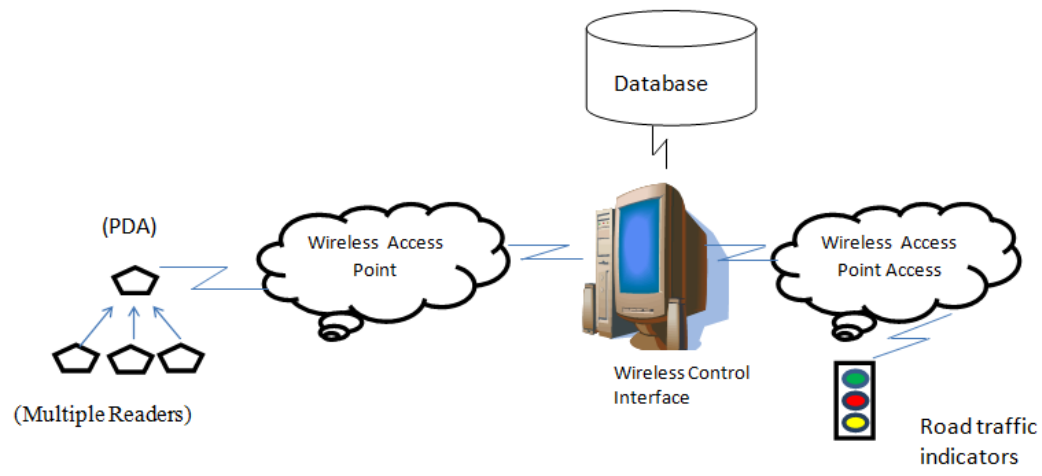

Figure 2.1: A frame work for Intelligent Road Traffic Signal Control System Using Multiple

Source: Field work Wireless Network Sensors (MWNS)

The generated value of the data read/observed/detected through the RFIR (Radio frequency Identification Readers) will be interpreted through the PDA (Personal Digital Assistance) and communicate to the central processor where the value(s) will be assigned to read data, add up and calculate for every road track; use the value to calculate the appropriate timing for the road signal illumination.

Control center for emergency vehicles on intelligent road traffic management system areconnected online to devices such as detectors on roads, cameras, traffic signals and so on, such a way that operators supervise/monitor the state of the road.The intelligent central controller determines time traffic illumination should stay on/off in a certain state, before switching to the next state. The order of states is predetermined based on the root content; that is, the vehicle volume or emergency contained in a root against other roots. The study was carried out on a cross road,and the following states were determined having compared volume and content of the vehicles on each of the roots on the cross junction road.

Table 2.1: $\quad$ State Determinant Table per Circle

\begin{tabular}{|c|c|c|c|c|c|c|c|c|}
\hline \multicolumn{9}{|c|}{ States Determined based on the Volume for a Particular Circle } \\
\hline Column 1 & Column2 & Column3 & Column4 & Column5 & Column6 & Column7 & Column8 & Column9 \\
\hline 苞 & Roads & $\begin{array}{l}\text { Numbers } \\
\text { of } \\
\text { Vehicles } \\
\text { assigned } \\
\text { per RFIR }\end{array}$ & $\begin{array}{l}\text { Numbers } \\
\text { of given } \\
\text { RFIR per } \\
\text { Road }\end{array}$ & $\begin{array}{l}\text { Numbers of } \\
\text { RFIR } \\
\text { contacted } \\
\text { with } \\
\text { Vehicle }\end{array}$ & $\begin{array}{l}\text { Value } \\
\text { assigned } \\
\text { per RFIR }\end{array}$ & $\begin{array}{l}\text { Numbers of } \\
\text { vehicles on } \\
\text { the Road }\end{array}$ & $\begin{array}{l}\text { Value } \\
\text { generated } \\
\text { by RFIR }\end{array}$ & $\begin{array}{l}\text { Green light } \\
\text { Illumination } \\
\text { per circle in } \\
\text { Seconds }\end{array}$ \\
\hline \multirow{4}{*}{ 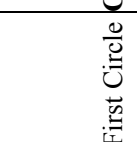 } & RoadA1 & 5 & 10 & 10 & 6 & 50 & 60 & 60 \\
\hline & RoadA2 & 5 & 10 & 4 & 6 & 20 & 24 & 24 \\
\hline & RoadB1 & 5 & 10 & 2 & 6 & 10 & 12 & 12 \\
\hline & RoadB2 & 5 & 10 & 8 & 6 & 40 & 48 & 48 \\
\hline
\end{tabular}

Source: Field work

Column1:This is Circle; stated that the whole four roads action (Road 1 to 4 ) is a set of circle.

Column 2:This is Roads; which stated the action(s) of each road on the cross junction, the actions can belong to any of the four roads, the action(s) do(es) not fixed to any particular road.

Column 3: This is Number of vehicles assigned per RFIR; state the number of vehicles a particular RFIR can $\mathrm{read} /$ access at a time.

Column 4:This is number of given RFIR(sensor) per Road, which is equal to 10 in here.

Column 5:Thisis numbers of RFIR(sensor) contacted with Vehicle, which is varies here; road $\mathrm{A} 1=10$, road $\mathrm{A} 2=4$, road $\mathrm{B} 1=2$, and road $\mathrm{B} 2=8$.

Column 6: This is Value assigned per RFIR (sensor) which is 6 here.

Column 7: This is number of vehicles on the road (that is column $3 *$ column5) which varies; $\operatorname{road} \mathrm{A} 1=50, \mathrm{road}$ $\mathrm{A} 2=20, \operatorname{road} \mathrm{B} 1=10, \operatorname{road} \mathrm{B} 2=40$.

Column 8: This is value generated by RFIR(sensor) (that is column5 * column6) which varies; road $\mathrm{A} 1=60, \operatorname{road} \mathrm{A} 2=24, \operatorname{road} \mathrm{B} 1=12, \operatorname{road} \mathrm{B} 2=48$.

Column 9: This is Green light Illumination per circle in Seconds, which varies; road $A 1=60$, $\operatorname{road} \mathrm{A} 2=24, \operatorname{road} \mathrm{B} 1=12$, road $\mathrm{B} 2=48$. Which is the value generated by the RFIR(sensor). 


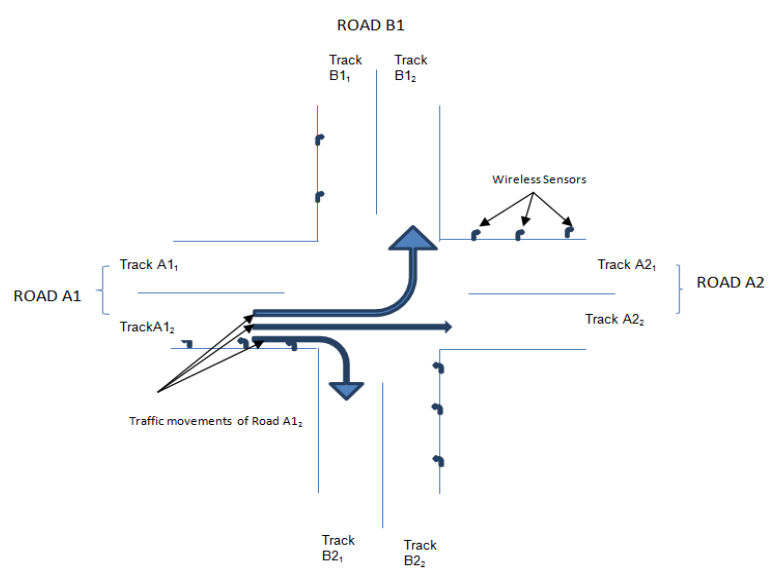

Figure 2.2: $\quad$ Roads Possible Traffic Movement at Particular Point in Time at a Cross Road Source: $\quad$ Field work

Figure 2.2 shows the possible traffic movement on Roads A1, A2, B1 and B2. Road A1 is divided into track $\mathrm{Al}_{1}$ and track $\mathrm{A} 1_{2}$, track $\mathrm{A} 1_{2}$ is the 'TO' track while track $\mathrm{A} 1_{1}$ is the 'FRO'.The possible tracks movements of each track depend on the state of the road traffic in action,Tack $\mathrm{A} 1_{2}$ contains tracks movement from West to track $\mathrm{B} 1_{2}$ of Road $\mathrm{B} 1$, track $\mathrm{A} 2_{1}$ of Road $\mathrm{A} 2$ and track $\mathrm{B} 2_{1}$ of Road $\mathrm{B} 2$. Road A2 is divided into track $\mathrm{A} 2_{1}$ and track $\mathrm{A} 2_{2}$, track $\mathrm{A} 2_{1}$ is the 'TO' track while track $\mathrm{A} 2_{2}$ is the 'FRO'. The possible tracks movements of each track depend on the state of the road traffic in action, Tack $\mathrm{A} 2{ }_{1}$ contains tracks movement from East to track $\mathrm{B} 1_{2}$ of Road B1, track $\mathrm{A} 1_{1}$ of Road $\mathrm{A} 2$ and track $\mathrm{B} 2_{1}$ of Road B2.Road B1 is divided into track $\mathrm{B} 1_{1}$ and track $\mathrm{B} 1_{2}$, track $\mathrm{B} 1_{1}$ is the 'TO' track while track $\mathrm{B} 1_{2}$ is the 'FRO'. The possible tracks movement of each track depend on the state of the road traffic in action, Tack $\mathrm{B} 1_{1}$ contains tracks movement from North to track $\mathrm{A} 1_{1}$ of Road A1, track $\mathrm{B} 2{ }_{1}$ of Road B2 and track $\mathrm{A} 2_{1}$ of Road $\mathrm{A} 2$. $^{*}$ Road $\mathrm{B} 2$ is divided into track $\mathrm{B} 2{ }_{1}$ and track $\mathrm{B} 2{ }_{2}$, track $\mathrm{B} 2_{2}$ is the 'TO' track while track $\mathrm{B} 2_{1}$ is the 'FRO'. The possible tracks movement of each track depends on the state of the road traffic in action, Tack $\mathrm{B} 2{ }_{2}$ contains tracks movement from South to track $\mathrm{A}_{1}$ of Road A1, track B1 2 of Road B1 and track $\mathrm{A} 2{ }_{2}$ of Road A2.

\subsection{Emergency Vehicle Priority Preference}

When traffic controller receives the request for service by the emergency vehicle, through the sensor; the controller will attempt to provide a green "ON" signal, by monitors the emergency vehicle's location and provides estimated time of arrivals to the various signalized intersections along the route minutes before the vehicle's arrival. The earlier the traffic controller receives the estimated time of arrival, the more time it has to adjust its cycle for the priority vehicle with the least amount of traffic disruption; by either going short in the cycle to allow for an early green, going long to extend the green, or doing nothing if the requesting vehicle will be arriving on green with no adjustment.

\section{Result}

Table3.1: $\quad$ ROOT A1 Traffic Movement Table Per Track

\begin{tabular}{|c|c|c|c|c|c|}
\hline & $\begin{array}{l}\text { Track } \\
\text { Movement } \\
\text { from }\end{array}$ & $\begin{array}{l}\text { Track } \\
\text { Movement to }\end{array}$ & $\begin{array}{l}\text { Greenlight } \\
\text { Illumination } \\
\text { State per circle } \\
\text { in Seconds }\end{array}$ & $\begin{array}{l}\text { Redlight } \\
\text { Illumination } \\
\text { State per circle } \\
\text { in Seconds }\end{array}$ & $\begin{array}{l}\text { Yellowlight } \\
\text { Illumination } \\
\text { State per circle } \\
\text { in Seconds }\end{array}$ \\
\hline 1 & Track $\mathrm{Al}_{2}$ & Track $\mathrm{B} 1_{2}$ & 60 & OFF & OFF \\
\hline 2 & Track $\mathrm{Al}_{2}$ & Track B2 2 & 60 & OFF & OFF \\
\hline 3 & Track $\mathrm{A} 1_{2}$ & Track B2 $2_{1}$ & 60 & OFF & OFF \\
\hline 1 & Track $\mathrm{A} 2_{1}$ & Track $\mathrm{B} 1_{2}$ & 24 & OFF & OFF \\
\hline 2 & Track $\mathrm{A} 2_{1}$ & Track B2 ${ }_{1}$ & 24 & $\mathrm{ON}$ & OFF \\
\hline 3 & Track $\mathrm{A} 2_{1}$ & Track $\mathrm{A} 1_{1}$ & 24 & $\mathrm{ON}$ & OFF \\
\hline 1 & Track B1 $1_{1}$ & Track B2 $2_{1}$ & 12 & $\mathrm{ON}$ & OFF \\
\hline 2 & Track B1 1 & Track $\mathrm{A} 2_{2}$ & 12 & $\mathrm{ON}$ & OFF \\
\hline 3 & Track B1 1 & Track $\mathrm{A} 1_{1}$ & 12 & OFF & OFF \\
\hline 1 & Track $\mathrm{B} 2_{2}$ & Track $\mathrm{B}_{2}$ & 48 & OFF & OFF \\
\hline 2 & Track $\mathrm{B} 2_{2}$ & Track $\mathrm{A} 2_{2}$ & 48 & OFF & OFF \\
\hline 3 & Track B2 2 & Track $\mathrm{A} 1_{1}$ & 48 & $\mathrm{ON}$ & OFF \\
\hline
\end{tabular}


Table 2 shows the possible tracks movement of the following tracks on a cross road at a point in time: from Road A1, Track $\mathrm{A}_{2}$ there will be movement to Road A2 TrackA2 for duration of 60 Seconds, Road B1 track $\mathrm{B} 1_{2}$ for duration of 60 Seconds andRoad B2 track B2 for duration of 60 Seconds. From Road A2, Track $\mathrm{A} 2_{1}$ there will be movement to Road A1 Track A $1_{2}$ for duration of 60 Seconds, Road B1 track B1 $1_{2}$ for duration of 60 Seconds and Road B2 track B2 1 for duration of 60 Seconds. From Road B1, Track B1 $1_{1}$ there will be movement to Road A2 Track A2 2 for duration of 60 Seconds, Road A1 track A1 1 for duration of 60 Seconds and Road B2 track B2 for duration of 60 Seconds. And finally from Road B2, Track B2 2 there will be movement to Road A2 Track A2 2 for duration of 60 Seconds, Road A1 track A1 for duration of 60 Seconds and Road B1 track $\mathrm{B} 1_{2}$ for duration of 60 Seconds

\section{Discussion}

Traffic signal illumination is determined based on the volume of vehicles present on each particular road; the sensors placed by the road sides read through its contact with the vehicles present on the highway at (cross road) and use the queue or volume of vehicles present on the road at the point in time to supply information to the Table 1 located in the database. The green light illumination is determined by multiplying column headings: (Numbers of RFIR contacted with Vehicle) by (Value assign per RFIR), the result which titled (Green light Illumination per circle in Seconds) then will determine the green light illumination time. However the traffic controller receives the request for service by the emergency vehicle, through the sensor; will attempt to provide a green signal by either going short in the cycle to allow for an early green, going long to extend the green, or doing nothing if the requesting vehicle will be arriving on green with no adjustment.

Table 1 is adatabase information showing the states determinant information of a particular cross road at a point in time, (That is, at a glance/vehicles present at once) on a cross roads where the Intelligent roadtraffic signal is highly in active. Figure 1 show the track movement of a particular cross road at a point in time and Table 2 show the varied in green light illumination which was determined by the volume of the road/track congestion. Movements fromTrack $\mathrm{Al}_{2}$, has the highest seconds of green light illumination of 60 seconds been having highest volume of 60 vehicles on its track, follow by Track $\mathrm{B} 22_{2}$, has the second in highest seconds of green light illumination of 48 seconds been having next highest volume of 40 vehicles on its track, follow by Track $A 2_{1}$, has the third in highest seconds of green light illumination of 24 seconds been having third highest volume of 20 vehicles on its track and finally Track $\mathrm{B} 1_{1}$, has the least seconds of green light illumination of 12 seconds been having least volume of 10 vehicles on its track. However when the detector(s) receive an acceptable incoming transmission on emergency vehicles on any of the tracks, priority will be given to the track and a relay will send to the traffic controller to preempt the signal for the oncoming emergency vehicle. Preemption works by forcing the controller out of its current operation and into a preconfigured pre-emptive state. Once the traffic controller receives a preempt signal, it begins the sequence to bring the controller into the preemptive state. This includes terminating vehicle phases, overlaps, and pedestrian phases not called for in the preemption.

\section{Conclusion}

The applied Multiple Wireless Network Sensors (MWNS) is an intelligent Road Traffic Signal to control vehicle traffic and provide priority preference for emergency vehicle(s). It helped to decongest the urban cross highways by dynamically rotating the state/time allocation for each state/per cycle based on road track volume and content at any point in time. The system monitors the emergency vehicle's location and provides estimated time of arrivals to the various signalized intersections along the route minute before the emergency vehicle's arrival. The earlier the traffic controller receives the estimated time of arrival, the more time it has to adjust its cycle for the priority vehicle with the least amount of traffic disruption. This will help to prevent unwanted incidence like an accident, unnecessary delay/collision of emergency vehicles.

\section{References}

[1] K. M. Yousef, J. N. AL-karaki and A. M. Shatnawi, Intelligent Traffic Light Flow Control System Using Wireless Sensors Networks. Journal of Information Science and Engineering, 26, 2010, 753-768.

[2] C. T. Wannige and D. U. J. Sonnadara, Adaptive Neuro-Fuzzy Traffic Signal Control for Multiple Junctions. IEEE International Conference on Industrial and Information Systems (ICIIS), 4, 2009, 262-267

[3] B. K. Sarika, and P. D. Gajanan, Design of Intelligent Ambulance and Traffic Control, International Journal of Innovative Technology and Exploring Engineering (IJITEE) ISSN: 2278-3075, (2)5, 2013, 211-214

[4] U. C. Osigwe, O. F. Oladipo and E. A. Onibere E. A, Design and Simulation of an Intelligent Traffic Control System, International Journal of Advances in Engineering \& Technology, 1(5), 2011, 47-57.

[5] A. K. Muhammad, PLC Based Intelligent Traffic Control System, International Journal of Electrical \& Computer Sciences, 11(6), 2011

[6] C. B. Gültekin, S. Murat and B. Oğuz, A Neural Network Based Traffic-Flow Prediction Model, Mathematical and Computational Applications, 15(2),2010, 269-278

[7] Y. P. Singh and K. M. Pradeep, Analysis and Designing of Proposed Intelligent Road Traffic Congestion Control System with Image Mosaicking Technique, International Journal of IT, Engineering and Applied Sciences Research (IJIEASR). 2(4), 2013, 2731. www.irjcjournals.org 
[8] R. Dinesh and K. Swapnili, Intelligent Traffic Signal Control System Using Embedded System, Innovative Systems Design and Engineering, 3(5). Retrieved June 7, 2013 from www.iiste.org

[9] R. K, Ashley, J. L. Soon and J. K. Yoo, Traffic Signal Systems: A Review of Current Technology in the United States. Science and Technology 3(1), 2013, 33-41

[10] L. Zhiyong, A Survey of Intelligence Methods in Urban Traffic Signal Control., IJCSNS International Journal of Computer Science and Network Security, 7(7), 2007, 105-111

[11] W. Wen, A dynamic and automatic traffic light control expert system for solving the road congestion problem. Elsevier. 34, 2008, $2370-2381$

[12] K. Peter, and R. John. Detection Range Setting Methodology for Signal Priority, Journal of Public Transportation, 5(2), 2002, 115 $-135$ 